\title{
Macaristan Kuman-Kıpçaklarından Kalan Bir Sayışmaca Üzerine Dilbilimsel Açıklamalar*
}

\author{
Hakan AYDEMIR**
}

Öz

Bu çalışmada Macaristan’ın Büyük Kumanistan (Nagykunság) bölgesinden derlenmiş, eskicil özellikler gösteren ve kimi noktaları şimdiye kadar tam olarak anlaşılamamış Kuman-Kıpçakça bir sayışmaca ve değişkeleri üzerinde durulmaktadır. Çalışmada, Türkiye'deki sayışmacalardan da iyi bilinen "alçık, balçık sen çık!'” kalıbıyla biten bu sayışmacanın ilk kısmındaki birem, íkem, öcsém, vb. biçimlerin şimdiye kadar sanıldı̆̆ gibi birinci tekil kişi $+(X) m$ iyelik ekli biçimler olarak değil (*bir $+i m$, *iki+im, *üç+üm, vb.), Onogur-Bulgar Türkçesine özgü olan eskicil $+(I) m$ sıra sayı ekli biçimler olarak anlaşılması gerektiği ileri sürülmektedir (birem < *bir+im 'birinci', ikem $<* i k i m<* \dot{e k i}+m / * \dot{e} k k i+m$ 'ikinci', öcsém $<* \ddot{u c ̧}+i m$ ‘üçüncü’ vb.). $\mathrm{Bu}+(I) m$ sıra sayı ekinin kullanıldığı sayışmacaların “alçık, balçık sen çık” kalıbıyla kombinasyonu sonucunda ortaya çıkan farklı biçimlerin kronolojik tabakaları da çalışmanın sonunda bir şema halinde gösteriliyor. Kuman-Kıpçakçası yanında, Kazakça, Tatarca, Başkurtça ve hatta Türkçe Türkçesindeki kimi tekerleme ve sayışmacalarda da görülen ve aslında Bulgar Türkçesi kökenli olan birim, ikim gibi sıra sayılarının bu dillere nasıl geçtiğini anlamak için çalışmanın sonunda Kuman-Kıpçakların tarihine ve göçlerine de kısaca değinilmektedir.

Anahtar Kelimeler: Kuman-Kıpçaklar, sayışmaca, sıra sayı eki, Bulgar Türkçesi sıra sayıları

\footnotetext{
* Bu çalışma TDK tarafından düzenlenen VII. Uluslararası Türk Dili Kurultayı'nda (24 - 28 Eylül 2012, Ankara) sunulan aynı başlıklı bildirinin tam metnidir.

** Dr. Öğretim Üyesi, İstanbul Medeniyet Üniversitesi, Dil Bilimi Bölümü. Türkiye

Elmek: aydemirhakaan@gmail.com
} 


\title{
Linguistic explanations on a counting-out rhyme inherited from the Kuman-Kipchaks in Hungary
}

\begin{abstract}
This study dwells on a Kuman-Kipchak counting-out rhyme with archaic features and its variants, which were compiled from the Greater Kumania (Nagykunság) region in Hungary and have not been fully understood at some points up to now. Contrary to earlier opinions, this study suggests that the forms birem, ikem, öcsém, etc. at the first part of this counting-out rhyme, which ends with the rhyme "alçık, balçık sen çık” well-known from Turkish counting-out rhymes, must be analysed as forms having the archaic ordinal number suffix $+(I) m$ characteristic of Onogur-Bulgar-Turkic (i.e. birem < *bir+im 'first', ikem $<i k i m<\dot{e} k i+m / \dot{e} k k i+m$ 'second', öcsém < üç+im 'third' etc.), and not as forms with the first-person singular possessive suffix $+(X) m$ (i.e. *bir $+i m$, *iki+im, *üç+üm, etc.). Chronological layers of different forms emerged as a result of the combination of the counting-out rhymes having the ordinal number suffix $+(I) m$ and the rhyme "alçık, balçık sen çık", are shown in a diagram at the end of the study. The ordinal numbers birim, ikim etc., which are originally of Bulgar-Turkic origin, can also be found in some tongue twisters and counting-out rhymes in Kazakh, Tatar, Bashkir and even in Turkish besides KumanKipchak language. In order to understand how these Bulgar-Turkic ordinal numbers got into these languages, the history and migrations of Kuman-Kipchaks are briefly mentioned at the end of the study.
\end{abstract}

Keywords: Kuman-Kipchaks, counting-out rhyme/game, ordinal number suffix, Bulgar-Turkic ordinal numbers. 
Doğu Avrupa'ya ilk olarak 11. yüzyılda ulaşan fakat bugünkü Macaristan topraklarına 13. yüzyılda yerleşmiş olan Kuman-Kıpçaklar tarih boyunca Macarlara katılmış ve asimile olmuş çeşitli Türk halklarının en sonuncusudur. Göçebe yaşam biçimlerini, geleneklerini ve dillerini burada nispeten uzun bir süre koruyabilmiş olmalarına rağmen sonunda yerleşik yaşama ve Hristiyanlığa geçerek zamanla Macarlaşmış ve dillerini tamamen unutmuşlardır.

1588 tarihinde Macaristan'1 da ziyaret eden Türk seyyah Şeyh Ali, Tatar olarak adlandırılan Kuman-Kıpçakların iki dilli olduklarını, Macarca yanında kendi dillerini konuştuklarını da belirtir. ${ }^{1}$ Fakat 17 . ve daha sonraki yüzyıllara ait kaynaklarda kendilerinden, farklı dil kullanan bir azınlık olarak söz edilmemesi Kuman-Kıpçakların 17. yüzyılda dilsel bakımdan artık tamamen Macarlaşmış olduklarını gösteriyor. Öte yandan, Latince yazılmış çeşitli kaynaklarda Macarlaşan bu Kuman-Kıpçaklar arasında aslen Müslüman olan, fakat Hristiyanlaşmış Kuman-Kıpçakların da olduğunu görüyoruz. ${ }^{2}$ Macarlaşan bu Kuman-Kıpçaklardan kalan sözcükler, kişi ve yer adları, sayışmacalar ve dualar ise bir "kültür mirası" olarak geçmişte olduğu gibi günümüzde de sadece konunun uzmanları tarafından değil, Macaristan'ın Küçük Kumanistan ve Büyük Kumanistan diye adlandırılan bölgelerinde yaşayan Macar ve Kuman-Kıpçak kökenli araştırmacıların ve aydınların da ilgisini çekmektedir. Hatta bu dil kalıntılarından Hristiyanlığa ait kısa bir duanın Kumanca çevirisi, daha doğrusu Kumanca çevirisinin zamanla bozulmuş değişkesi Kuman-Kıpçak kökenlerine sahip çıkan Küçük ve Büyük Kumanistan bölgesindeki kimi şehirlerin liselerinde ders kitaplarına da alınmış ve 1848'e kadar öğretilmişti. Günümüze ulaşmış bu dil malzemelerinin araştırılıp incelenmesi ve bilim dünyasına tanıtılması hem Türk-Macar dil ilişkileri açısından, hem de Türk dili tarihi ve Türk kültür tarihi açısından da önem arz etmektedir.

1 Bk. C. M. Fraehn, Veteres Memoriae Chasarorum ex Ibn-Foszlano, Ibn-Haukale et Schemseddino Damasceno: Mémoires de l'Academie Impériale des Sciences de St.-Petersburg VIII, 1822: 618-620 (Mándoky 1993: 13).

2 Bk. Aydemir 2009: 22. 
Bu düşünceden hareketle, bu çalışmada Macaristan'ın Büyük Kumanistan bölgesinden derlenmiş, sözvarlığı açısından eskicil özellikler gösteren ve kimi noktaları şimdiye kadar tam olarak anlaşılamamış Kuman-Kıpçakça bir sayışmaca ve değişkeleri üzerinde durulacaktır. ${ }^{3}$

İlk olarak belgelendiği 1840 'lı yıllardan beri çeşitli araştırmacılar tarafindan incelenen fakat tam olarak anlaşılamayan bu sayışmacanın Kuman-Kıpçakça kökenli olduğunu, genç yaşta aramızdan ayrılan, Kuman kökenli Macar Türkoloğu ve Kıpçakça uzmanı István Mándoky Kongur ortaya koymuştur.

Macaristan'daki Kuman-Kıpçak dil yadigârlarının araştııılması sadece Macar kültür tarihi açısından değil, Türk kültür tarihi ve dil tarihi açısından da önemlidir. ${ }^{4}$ Nitekim, sayışmacada geçen üzük ( üzik) 'yuvarlak keçe çadırların yan duvarlarında kullanılan keçe', senek 'ağaç dirgen', ${ }^{5}$ torsuk ( torsık) 'kımız tulumu', alçik $(<a l c ̧ ı)^{6}$ 'aşık' sözcükleri' ve şimdiye kadar yanlış anlaşılmış olan bírem (< birim 'birinci'), ikem (< ikim 'ikinci'), öcsém (< üçüm 'üçüncü') vb. gibi çok eskicil biçimler de bunu açıkça doğrulamaktadır. Sözü edilen üzük ( üzik), senek, torsuk ( torsık) ve alçik sözcüklerinin dil yadigarlarımız arasında ilk defa bu Kuman-Kıpçakça sayışmacada geçtiğini ve tarihi Bulgar-Türkçesine özgü olan eskicil $+(I) m$ sira sayı ekinin bírem $(<$ bir $+i m)$ 'birinci', ikem $(<$ ikim $<\dot{e} k i+m)$ 'ikinci', öcsém $(<\ddot{u} c ̧+\ddot{u} m)$ 'üçüncü' vb. gibi biçimlerde korunmuş olduğunu dikkate alacak olursak bu sayışmacanın Türk dili tarihi bakımından önemi kendiliğinden anlaşılacaktır. Fakat konuyla ilgili problemleri ele almadan önce konunun daha iyi anlaşılabilmesi için söz konusu Kuman-Kıpçakça sayışmaca hakkında Mándoky Kongur'un araştırma sonuçlarını ve çözüm önerilerini kısaca tanıtmakta yarar görüyorum.

Kuman-Kıpçakça sayışmaca, Macaristan'da bilinen öteki Kuman-Kıpçakça dil yadigârlarına göre oldukça geç ortaya çıkar. Bugünkü bilgilerimize göre Macar kaynaklarında 19. yüzyılın 40'lı yıllarından önce bu sayışmaca hakkında

\footnotetext{
3 Bk. aşağıda (1) numaralı değişke.

4 Mándoky 1993: 15.

5 Krş. DS senek II 'dört çatallı demir dirgen' (Afyon).

6 Eski ve Orta Türkçe kaynaklarda geçmeyen eskicil alçık sözcügü, günümüz Türk dillerinde sadece Karaçay-Balkarcada alçık ( aşık) olarak görülmektedir. Bu eskicil biçimi Rusçada - muhtemelen Bulgar Türkçesinden bir alıntı olarak - bugün de görmekteyiz; bk. Rusça alç'ik//альчик 'aşık'.

7 Bu sözcükler aşağıda (1) numaralı değişkede üszök, szenneg és torcog olarak görülürler.
} 
hiçbir kayda rastlanmıyor. ${ }^{8} 19$. yüzyılın 40 'lı yıllarında bu sayışmacanın iki değişkesi kayda geçmiş. İlk değişke, Karcag şehrindeki bir kürk ustasının not defterine 1841 ve 1848 tarihleri arasında not edilmiştir. ${ }^{9}$ Diğer değişke ise 1944 öncesinde, Kunmadaras şehrinde, el yazısıyla hazırlanmış bir kitapta geçmektedir. ${ }^{10}$ Şimdilik bu iki değişkeden daha eski tarihli başka örnek bilinmiyor. Fakat 20. yüzyılın ilk ve ikinci yarısında, Macaristan'da Küçük ve Büyük Kumanistan olarak adlandırılan iki bölgedeki okulların eğitsel kolları tarafından derlenmiş değişkeler de mevcuttur. Mándoky Kongur, eğitsel kollar tarafından derlenmiş olan değişkelerden en az bozulmuş olanlardan yedi sayışmacayı seçip karşılaştırarak ayrıntılı bir biçimde incelemişti. ${ }^{11}$ Bir kısmı artık tanınamayacak hale gelmiş bu yedi sayışmaca aşağıda görülebilir (Macaristan'da derlendikleri yer adı sayışmacanın sonunda parantez içinde verilmiştir).

Sayışmaca değişkeleri:

$\begin{array}{cccc}\text { (1) bérem bélö } & \text { (2) bírem bellö } & \text { (3) bérem bellö } & \text { (4) vírem velö } \\ \text { ékem égö } & \text { íkem ígö } & \text { ekém elö } & \text { ikem igö } \\ \text { öcsém üszök } & \text { ecsém eszi } & \text { este eszünk } & \text { ecsém eszik } \\ \text { kertem tücsök } & \text { törvin teszi } & \text { halesz veszünk } & \text { törve teccik } \\ \text { becsém becsek } & \text { bessem bessi } & \text { télre teszünk } & \text { álla vásik } \\ \text { állam hasad } & \text { áta láta } & \text { álla málla } & \text { gyepre vetik } \\ \text { csettem csetteg } & \text { sétre csétre } & \text { gyettem gyette } & \text { szegre szendik } \\ \text { szegzem szenneg } & \text { szegre szerre } & \text { szeggem szenne } & \text { toboz tórcok } \\ \text { togzom torcog } & \text { tózom torcog } & \text { toboz doboz } & \text { kónom kacska } \\ \text { hónom hagyta } & \text { kónyi kacski } & \text { kunom kaska } & \text { gyóvor kapta } \\ \text { gyürüm kapta } & \text { csupa tapsi } & \text { györi laska } & \text { adassíkfelesig } \\ \text { alcsík } & \text { se nem nagy } & \text { erepés terepés } & \text { egymást szeressík } \\ \text { balcsík } & \text { se nem kicsi } & \text { kazán tebén }{ }^{12} & \text { kardalés } \\ \text { szencsíg } & \text { te menj ki } & \text { (Karcag) } & \text { (Karcag) } \\ \text { (Kunmadaras) }^{13} & \text { (Karcag) } & & \end{array}$

\footnotetext{
8 Mándoky 1993: 72.

9 Bk. aşağıda (3) numaralı değișke.

10 Mándoky 1993: 72-73. Mándoky, kitabında bu değişkeden söz etmesine rağmen değişkeye yer vermemiş, neden yer vermediğini ise belirtmemiştir. Bu değişkenin bulunduğu söz konusu kitap, şahsi bir kolleksiyonda olduğu için tarafımızdan kontrol etme ve öteki değişkelerle karşılaşırma imkanı olmamıştır.

11 Bk. Mándoky 1993: 74-78. Bunlardan (7). değişkeyi Mándoky’nin kendisi Karcag șehrinde derlemiştir.

12 Dobruca Tatarlarına ait bir sayışmacanın 11. dizesinde kazantiup+te (Bk. Mándoky 1993: 79).

13 Sayışmacanın derlendiği şehir.
} 


$\begin{array}{ccc}\text { (5) berrem berrö } & \text { (6) bírem bellö } & \text { (7) erre mentem } \\ \text { ekkem eggö } & \text { íkem ígö } & \text { ékem vettem } \\ \text { iccsem izzeg } & \text { este eszik } & \text { este vittem } \\ \text { kertem tözeg } & \text { türbe türik } & \text { törve tettem } \\ \text { beskem besket } & \text { beske besik } & \text { becsembeltem } \\ \text { atta lássuk } & \text { anapé kanapé } & \text { attalaska } \\ \text { csetém csette } & \text { citapé csetepé } & \text { szengeleske } \\ \text { szeggel szélen } & \text { szette vette teremtette } & \text { togza torca } \\ \text { togza torcag } & \text { kinek vette levetette } & \text { komma kacska } \\ \text { kullon masta } & \text { itt van hé } & \text { kövér tapsi enikecsi } \\ \text { gyéren tapcsa } & \text { te menj ki } & \text { toroté karaté keresd hé } \\ \text { tenemícc menemícc } & \text { (Kunmadaras) } & \text { (Karcag) } \\ \text { te kimícc } & & \end{array}$

(Kisújszállás)

Yukarıdaki değişkelerden nispeten en iyi korunmuş olanı - aşağıda da göreceğimiz gibi - (1) numaralı değişkedir. Mándoky'nin belirttiğine göre, bu yukarıdakiler dışında pek çok anlamlı Macarca sözcük içeren, hatta anlamlı cümlelerden oluşan artık neredeyse tamamen Macarcalaşmış değişkeler de vardır. Burada tabii ki ağızdan ağıza yayılan ve içerdikleri Kuman-Kıpçakça sözcüklerin anlaşılamaması nedeniyle zamanla değişime uğramış ve sonunda neredeyse tamamen Macarlaşmış değişkeler söz konusu. Bu durumun doğal, hatta kanun niteliğinde olduğunu rahatlıkla ileri sürebiliriz. Çünkü sayışmacalar ağızdan ağıza, dilden dile yayılarak ana değişkeden ayrı, kendi başlarına bir değişim gösterirler ve bu değişim sürecinde sayışmaca içindeki kulağa yabancı gelen, anlaşılamayan sözcükler kullanıldığı bölgenin veya ülkenin dilindeki anlamlı veya anlamsız ya da ses yapısı benzer olan sözcüklerle değiştirilir. Yukarıdaki sayışmacalar buna iyi birer örnek olarak gösterilebilir.

Mándoky 1976’ya kadar bu yukarıdaki sayışmacaları Kuman-Kıpçakçadan açıklamaya çalışmış, fakat başarılı olamamıştı. 1976-1977 tarihlerinde Alma Ata'da Macaristan'daki sayışmaca ile kısmen aynı olan iki tekerleme buldu. ${ }^{14}$ 
(8)
(1. Kazakça değişke $)^{15}$
1. Birim - bir
2. Ekim - eki
3. Üşim - üş
4. Törtim-tört
5. Beşim - beş
6. Altım-alti
7. Jetim-jeti
8. Segizim - segiz
9. Togızım - togïz
10. Onim - on
11. On birim
12. Oni tapş 1
13. Ay, künim

(9)

(2. Kazakça değişke) ${ }^{16}$

1. Bir degenin-bilew

2. Eki degenin-egew

3. Üş degenin - üski

4. Tört degenin - tösek

5. Bes degeniy-besik

6. Altı degenin-asık

7. Jeti degenin - jelke

8. Segiz degenin - serke

9. Togiz degenin-torka

10. On degeniy - oymak

11. On bir kara-jumbak

Mándoky, bu Kazakça tekerlemelerden 1. değişkedeki birim ve 2. değişkedeki bilew ile başlayan sıraları birleştirerek ilk bakışta Macarca gibi görünen (1) numaralı Kuman-Kıpçakça sayışmacanın (bk. daha yukarıda) ilk 9 satırının rekonstrüksiyonunu şöyle yaptı:
(Kunmadaras)
(Mándoky'nin rekonstrüksiyonu)
(Mándoky'nin çevirisi $^{17}$
1. bérem bélö
1. birim bilew
1. birim bileği $(<b i r+$ iyelik eki)
2. ékem égő
2. ekim egew
3. öcsém üszök
3. üçüm (üçim) üzük (üzik)
2. ikim eğe $(<i k i+$ iyelik eki)
4. kertem tücsök
4. törtüm (törtim) töşek
3. üçüm çadır örtüsü keçe,
5. becsém becsek
5. beşim beşik
4. dördüm döşek
6. állam hasad
6. altım aşık
5. beşim beşik
7. csettem csetteg
7. cetim ...
6. altım aşık
8. szegzem szenneg 8. segizim senek
7. yedim .......
8. sekizim ağaç dirgen

15 Mándoky'nin Macarca çevirisi şöyle: 1. 'Egyem - egy, 2. Kettőm - kettő, 3. Hármom - három, 4. Négyem - négy, 5. Ötöm - öt, 6. Hatom - hat, 7. Hetem - hét, 8. Nyolcom - nyolc, 9. Kilencem - kilenc, 10 Tizem - tíz, 11 Tizenegyem, 12 Azt találd csak ki, 13 Hold[am], napom' (Mándoky 1993: 84).

16 Mándoky’nin Macarca çevirisi şöyle: 1. 'Egyet mondottad - fenykő, 2. Kettőt mondottad - reszelö, 3. Hármat mondottad - fúró, 4. Négyet mondottad - ágy, 5. Ötöt mondottad - bölcső [!],6. Hatot mondottad - bokacsont, 7. Hetet mondottad - tarkó, 8. Nyolcat mondottad - herélt kecskebak, 9. Kilencet mondottad - selyem, 10 Tizet mondottad - gyüszű, 11 Tizenegy[et], lásd - [egy] találoskérdés' (Mándoky 1993: 81). Aynı tekerlemeyi ufak farklılıklarla Karakalpaklarda da görmek mümkün, Bk. KklpBask, s. 90.

17 Mándoky’nin Macarca çevirisi șöyle: egyem - fenykő, 2. kettőm - reszelö, 3. hármom - nemeztakaró-nemez, 4. négyem - fekhely, 5. ötöm - bölcső, 6. hatom - játszó (juh-)bokacsont, 7. hetem - ... (eksik) ..., 8. nyolcom - favilla, 9. kilencem - börtömlö, 10. -11. Satırların rekonstrüksiyonunu yapamadığı için bu satırların çevirisini vermemiş. 


\begin{tabular}{|c|c|c|}
\hline 9. togzom torcog & 9. toguzum torsuk & 9. dokuzum tulum \\
\hline 10. hónom hagyta & $10 \ldots$ & $10 . \ldots$ \\
\hline 11. gyürüm kapta & 11.) $\ldots$ & $11 \ldots \ldots \ldots \ldots \ldots$ \\
\hline 12. alcsik & $12 \ldots$ & $12 \ldots \ldots \ldots \ldots \ldots$ \\
\hline 13. balcsik & $13 \ldots$ & $13 \ldots \ldots \ldots \ldots \ldots \ldots$ \\
\hline 14. szencsig & $14 . \ldots$ & $14 \ldots \ldots \ldots \ldots \ldots$ \\
\hline
\end{tabular}

Mándoky daha sonra Macaristan'ın Karcag şehrinde, Karaçaylar arasında 40 yıl yaşamış István Höge adlı bir Macardan Kazakça tekerlemenin bir başka değişkesini derlemiş ve Karaçayca değişkedeki sözcükler yardımıyla (1) numaralı Kuman-Kıpçakça sayışmacada 1. sıradaki bilew 'bileği', 2. sıradaki egew 'eğe', 5. sıradaki beşik 'beşik', 6. sıradaki aşık 'aşık' ve 8. sıradaki senek 'ağaç dirgen' sözcüklerinin rekonstrüksiyonunu bu şekilde bir kez daha doğrulamıştı. Mándoky Kongur'un Macaristan'da derlediği Karaçayca tekerleme şöyle:18

$\begin{array}{ll}\text { 1. birden bileü } & \text { 8. segizden senek } \\ \text { 2. ekiden egeü } & \text { 9. toguzdan tokmak } \\ \text { 3. üçden üçgül } & \text { 10. ondan oymak } \\ \text { 4. törtden töngek } & \text { 11. buzdan taymak } \\ \text { 5. beşden beşik } & \text { 12. abbel bilim } \\ \text { 6. altıdan aşık } & \text { 13. çıssın tilì } \\ \text { 7. cetiden kaşık } & \end{array}$

Bu yukarıdaki açılamalardan, Mándoky Kongur'un (1) numaralı KumanKıpçakça sayışmacada - $m$ ile biten birim, ekim, üçüm gibi sözcükleri 1. tekil kişi iyelik ekli biçimler olarak gördüğü, 7. ve 10-14. sıradaki sözcüklerin rekonstrüksiyonunu ise benzer örnek bulamadığı için yapamadığı anlaşılıyor. Aşağıda, Mándoky Kongur'un elde ettiği değerli sonuçları da dikkate alarak yeni veriler yardımıyla Kuman-Kıpçakça sayışmacanın rekonstrüksiyonunu bir adım daha ileri götürecek çözümler üzerinde duracağım.

Macaristan'ın Küçük ve Büyük Kumanistan diye adlandırılan bölgelerinden derlenen söz konusu sayışmaca ve değişkelerine iliş̧in ilk akla gelen soru bu sayışmacanın gerçekten Kuman-Kıpçak kökenli olup olmadığıdır. Bu soruya 
'evet' ile cevap verebiliriz, çünkü (1) numaralı değişkede sesbilgisel bakımdan artık Macarcalaşmış 1. ve 2. sıradaki bélö $(<*$ bileü <*bilew 'bileği', krş. CCI bilev $<*$ bileg) ve égö 'eğe' $(<*$ egeü $<*$ egew <*egeg) sözcükleri kurallı olarak *bilew ve * egew sözcüklerine geri gider. Söz sonundaki -ew ise Kıpçakça bir özelliktir ve bu iki sözcüğün Kuman-Kıpçak kökenine açık bir kanıttır. Kazakçadaki bilew ve egew biçimleri de bunu doğrulamaktadır.

İkinci soru, Küçük ve Büyük Kumanistan bölgelerinden derlenen yukarıdaki 7 sayışmacanın tek bir sayışmacanın mı, yoksa farklı sayışmacaların mı değişkeleri olduğudur. Mándoky Kongur bu soru üzerinde durmamıştır. Fakat görüldüğü kadarıyla yukarıdaki 7 sayışmacadan (1) ve (3) numaralı değişkeler farklı biçimde sonlanıyorlar. Nitekim nispeten en iyi korunmuş olan (1) numaralı sayışmaca szencsíg (< sen çık) ile biterken, (3) numaralı sayışmaca kazán tebén $(<\text { ? kazan tüb }+i+n / \text { tüp }+i+n \text { 'kazan dibini' })^{19}$ ile sonlanır. Bu sonuncusu, Dobruca Tatarlarına ait bir sayışmacanın 11. sırasında kazantuip +te 'kazan dibinde' (< kazan tüp + te) biçiminde de karşımıza çıkıyor, bkz.:
1. bir dedim birlew
10. on dedim oymaq
2. eki dedim ekilew
11. kazantipte kaymak
3. uş dedim usslew
12. viy aldinda boz tana
4. dort dedim dortlew
13. kolvatada kayqana
5. beş dedim beşlew
14. alpak malpak
6. altı dedim alma
15. tabanlarl calpak
7. yedi dedim yalma
16. komşı kòge cetiyim
8. sekiz dedim selma
17. seni maktap ketiyim ${ }^{20}$
9. dokuz dedim dolma

(3) numaralı sayışmacanın (1) numaralı sayışmacadan farklı olarak kazán tebén ile sonlanması, Büyük Kumanistan bölgesinden derlenen sayışmacaların en az iki değişkesi olduğuna işaret ediyor.

Üçüncü soru, Mándoky Kongur'un benzer örnek bulamadığı için rekonstrüksiyonunu yapamadığı 7. ve 10.-14. satırların rekonstrüksiyonun mümkün olup olmadığıdır. 7., 10. ve 11. satırların rekonstrüksiyonu benzer örnek olmadığı için şimdilik mümkün görünmüyor, fakat Türkiye'deki çocuk edebiyatından ve-

19 Krş. Codex Cumannicus kazan 'kazan' ve tüp, tüb ‘dip, zemin'.

20 Mándoky 1993: 79. 
receğimiz örneklerle 12., 13. ve 14. satırların rekonstrüksiyonunu kesin olarak yapabiliriz. Aşağıdaki (13) numaralı Türkçe sayışmacanın 5. ve 6. satıllarının, Macaristan'daki Kuman-Kıpçakça kökenli (1) numaralı sayışmacanın son bölümüyle harfiyen uyuştuğunu görüyoruz, bkz.:

\section{Bir iki}

2. Kurnaz tilki

3. Findlk, fistlk

4. Kadifeden yastik

5. Alçı balçık

6. Sen $\iota^{21}$

Türkiye çocuk edebiyatında yaygın olarak görülen alçık / balçık / sen çık kalıbının hem sayışmaca olarak tek başına, hem de başka sayışmacaların son kısmını teşkil eden ve sana dedim, saydım, durma, sen dur, gel sen gibi sözcüklerle genişletilmiş birçok değişkesi var.

\begin{tabular}{|c|c|c|c|}
\hline Edin nene, & Findlk fistik, & Al çık bal çık. & Al çık bal çık \\
\hline Bedin nene, & Kadife yastık. & Sana diyorum & Aradan önce \\
\hline Suya düşmüş, & Amanin yenge, & Sen çı!! $!^{22}$ & Sen çık! ${ }^{23}$ \\
\hline Kadın nene! & Ben yapmadim, & & \\
\hline Al çık, bal çık. & Horoz yapti. & & \\
\hline Sen dur, & $A l c ̧ ı k, b a l c ̧ ı k$ & & \\
\hline Sen çık! $!^{24}$ & Saydım sen çı $k^{25}$ & & \\
\hline
\end{tabular}

Görüldüğ̈̈ gibi, Macaristan'ın Kunmadaras şehrinde derlenen (1) numaralı sayışmacanın sonundaki Mándoky'nin rekonstrüksiyonunu yapmadığı alcsik / balcsik / szencsíg ifadeleri ile Türkiye'de yaygın olarak bilinen alçık / balçık / sen çılk! kalıbı tamamen aynı. Bu durum sadece Kuman-Kıpçakça sayışmacanın son kısmının rekonstrüksiyonu açısından değil, bugünkü $a s ̧ ı$ sözcüğünün en eski biçimi olan alçık (> aşık) sözcüğünün söz konusu Kuman-Kıpçakça sayışmacada korunmuş olması bakımından da önemli. Bu alçık sözcüğünün Türkiye'de yaygın

\footnotetext{
21 Bu sayışmaca, Manisa'nın Turgutlu ilçesinden derlenmiş, Bk. Elçin 2010:593. Aynı değişke Giresunda da biliniyor. 22 Akın 2010: 7.

23 Akın 2010: 7.

24 Akın 2010: 54

25 Akın 2010: 63 .
} 
olarak görülen alçık / balçık / sen çık! sayışmacası dışında (Rusçadaki alçik hariç) eski hiçbir kaynakta geçmediğini dikkate alırsak, bu kalıbın korunduğu KumanKıpçakça sayışmacanın önemi sanırım kendiliğinden anlaşılacaktır.

Anadolu'da artık giderek kaybolmakta olan, fakat Orta Asya Türk halklarında ve Moğollarda yaygın olarak görülen çeşitli aşık oyunlarını sadece çocuklar değil, yetişkinler de oynar. Bir derlemeye göre Moğollarda - genellikle kırsal bölgelerde - çocuklar bugün de tartışmalı konularda veya oyunlarda kararlarını kura çekimi yerine aşık oyunları yardımıyla verirler. ${ }^{26} \mathrm{Bu}$ analojiye ve Türkçedeki alçık / balçık / sen çık! kalıbına dayanarak, aşığın Türklerde de en eski dönemlerde ebe seçiminde ve oyundan çıkarmada kullanıldığını düşünebiliriz.

Yukarıdakilere dayanarak Kuman-Kıpçakça sayışmacanın sonundaki alcsík / balcsik / szencsíg! ve Anadolu'da yaygın olarak görülen alçık / balçık / sen çık! kalıbının aslen aşık oyunlarında kullanılmış bir kalıp olduğunu düşünüyorum. $A s ̧ \iota k(<a l c ̧ ı k<* a l c ̧ ı+(I) k$ ?) sözcüğünün eskicil biçimi olan alçıl ve Anadolu'daki aşık oyunu terminolojisindeki bal ve çık sözcüklerinin birleşmesinden meydana gelmiş olması muhtemel olan balçı $k^{27}$ sözcüğü zamanla aşı oyununu ve bu sözcükleri tanımayan çocukların veya yetişkinlerin dilinde gerçek anlamları unutulmuş uyaklı sözcükler olarak kullanılmaya başlamış olmalı. ${ }^{28}$ Türkiye'deki çocuk oyunlarından bilinen ve yukarıda (16) ve (17) numaralı örneklerde geçen Al çık / Bal çık / Sana diyorum / Sen çık! ile Al çık / Bal çık/Aradan önce / Sen çık! sayışmacalarında aslen bitişik yazılması gereken alçık ve balçık sözcüklerinin al $c ̧ \iota k$ ve $b a l$ çık diye ayrı ayrı yazılmaları da bu sayışmacaları kullanan veya kaydeden kişilerin bu iki sözcüğü artık anlamadıklarını ve bu iki sözcüğe farklı anlamlar yüklediklerini gösteriyor. Bu kalıbın kullanıldığı sayışmacaların tabakalarını ve tipolojisini bu çalışmanın sonundaki şemada ayrıntılı olarak görmek mümkün.

Söz konusu Kuman-Kıpçakça sayışmacaya ilişkin dördüncü ve belki de en önemli soru, bu Kuman-Kıpçakça sayışmacadaki bérem, ékem ve Kazakça te-

26 Farkas 1987: 59.

27 Macarca balcsik $\leftarrow$ Kuman-Kıpçakça *balçık< ? bal +çık, krş. DS bal 'Çocukların oyun oynadıkları aşıkların girintili çıkıntılı kısımları' + DS çık 'Aşı1 kemiğinin çukur tarafi'. Bu etimolojik çözümün sadece bir çalışma varsayımı olduğunu burada özellikle belirtmek isterim.

28 Balçık sözünü burada *balç 'baş' ve küçültme eki +(I)k olarak, yani *balç+(I)k> balçık şeklinde çözümlemek de mümküm. Bu durumda bu sayışmacadaki balçık sözüne 'baş, başcık; öncü' anlamı verebiliriz. Anadolu'da bir aşı oyunu terimi olarak kullanılan öncü terimi de anlam bakımından böyle bir etimolojik çözümlemeyi destekleyebilir. Fakat muhtemelen Türkçenin çok erken dönemlerinde ortaya çıkan bu sayışmacaya hangi aşık oyununun temel olduğunu ve balçık sözünün ortaya çıkmasındaki motivasyonu bilmediğimiz için bu iki etimolojik çözüm önerisinin doğru olup olmadığına karar vermek oldukça zor. Dolayısıyla bu etimolojik çözüm de ancak bir çalışma varsayımı olarak görülebilir. 
kerlemedeki birim, ikim vb. biçimlerinin, Mándoky Kongur ve Macaristan'daki başka birkaç araştırmacının ${ }^{29}$ düşündüğü gibi 1. tekil kişi iyelik ekli biçimler olup olmadığıdır. Söz konusu biçimlerin iyelik ekli biçimler olduğu fikrine katılm1yorum. Kanımca bu biçimlerde 1. tekil kişi $+(X) m$ iyelik ekinden değil, Bulgar Türkçesindeki $+(I) m$ sıra sayı ekinden söz etmemiz gerekiyor. ${ }^{30}$ Volga Bulgarcası (13-14. yy.) ve Tuna Bulgarcası (8. yy.) dil yadigârlarında görülen birim 'birinci' < *bir+im (= Kuman-Kıpçakça sayışmacadaki bírem bérem, Kazakça tekerlemedeki birim, Başkurtça ve Tatarca tekerlemelerdeki birrem, Türkçe tekerlemelerdeki birim birem) ve wečim, večim 'üçüncü' < *üč+im (> Kuman-Kıpçakça sayışmacadaki öcsém ecsém, Kazakça tekerlemedeki üşim, Türkçe tekerlemelerdeki üçüm, Başkurtçadaki ösem, Tatarcadaki öčem) sıra sayı adları da bu görüşü açıkça destekliyor. Kuman-Kıpçakça ve Kazakça sayışmacalarda geçen ve aslen sıra sayı adları olduğunu düşündüğüm benzeri biçimlere Tatarca, Başkurtça tekerlemeler ile kimi Türkçe tekerlemelerde de rastllyoruz. Şimdi bu örneklere kısaca bir göz atalım. İlk örneğimiz Başkurtçadan:

(18) "Берәм - бәрәм, икәм-китәм, өсәм-сәсәм, дүртәм-төртәм, бишәм-бешәм, алтам-ватам, етәм-этәм, ауыр балтам, алтын балтам". ${ }^{31}$ (Başkurtça)

'Один - кину, два - уйду, три - разбросаю, четыре - толкну, пять - распеку, шесть сломаю, семь - толкну, мой тяжелый топор, мой золотой топор' ${ }^{32}$ (Rusça çevirisi) 'Bir, vuruyorum; iki, gidiyorum; üç, saçıyorum; dört, dürtüyorum; beş, azarlıyorum; altı, ufaltıyorum; yedi, iteliyorum; ağır baltam, altın baltam'. (Türkçe çevirisi)

Görüldüğ̈̈ gibi Başkurtça tekerlemede birem, ${ }^{33}$ ikem (Берәм, икәм) sözcüklerindeki $+e m(=+\partial m)$ eki 1. tekil kişi iyelik eki olarak çevrilmemiştir. Başkurtçada $+(I) m$ sıra sayı eki olmadı̆̆ından ve b̆rem, ikem gibi, aslında sıra sayısı olan biçimlerin sadece bu tekerlemede görülmesinden ve gerçek anlamlarını artık yitirmiş olmalarından dolayı bu biçimler Rusçaya sadece sayı adı olarak одuн 'egy', два 'kettő' vb. diye çevrilmişlerdir. Bu bakımdan Rusça çevirisinin doğru olduğunu söyleyebiliriz.

Söz konusu b̆̌rem, ikem biçimlerini Tatarca bir sayışmacada da görüyoruz.

29 Bk. Torma 1999: 92-93, Kakuk 1993: 313-315, Mukusheva 2008: 148.

30 Bu sıra sayı eki hakkında bk. Tekin 1988; 40, Erdal 1993: 106, Stachowski 1994: 177-183, krş. Ercilasun 2007: 9.

31 Hisamitdinova 2010: 53.

32 Hisamitdinova 2010: 53.

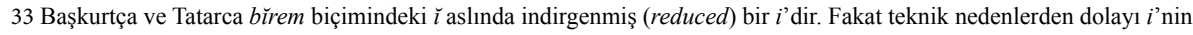
noktası burada yazılamamıştır. 
Muhametşin ve Hakimzyanov adlı araştırmacılar, Volga Bulgar mezar kitabeleri üzerine hazırladıkları bir kitapta aşağıdaki sayışmacayı veriyorlar. ${ }^{34}$

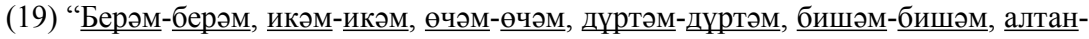
алтан — авыр балтам ..." ${ }^{35}$ (Tatarca)

'Один-один, два-два, три-три, четыре-четыре, пять - пять, шесть - шесть, тяжелый топор .... ${ }^{36}$ (Rusça çevirisi)

'Birim - birim, ikim - ikim, üçüm - üçüm, dördüm - dördüm, beşim - beşim, altım altım, ağır baltam ...' (Türkçe çevirisi)

Görüldüğü gibi bu Tatarca sayışmaca, yukarıdaki Başkurtça tekerlemenin

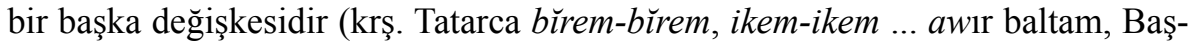
kurtça b̆̌rem, ikem ... avır baltam). Rusça çevirisinden de anlaşıldı̆̆ı gibi, Muhametşin ve Hakimzyanov buradaki b̆̌rem, ikem biçimlerini 1. tekil kişi iyelik ekleri olarak değil, sayı adları olarak çevirmişler (один-один, два-два 'bir-bir, iki-iki'). Bu çevirinin de doğru olduğunu belirtmemiz gerekir, çünkü $+e m(=+\partial m)$ ekinin ikili kullanımlarında $(+e m$... + em ...) bu ekleri başka türlü çevirmek zaten mümkün de değildir. Bu durum, aşağıda göreceğimiz Türkçe tekerlemelerdeki birem birem - ikem ikem kalıpları için de geçerlidir. Nitekim Muhametşin ve Hakimzyanov adlı araştırmacılar, Tatarca sayışmacadaki $+e m(=+\partial \mu)$ ekinin asıl işlevini doğru olarak anlamış ve bu ekin aslında 'sıra' bildiren bir ek olduğunu ve Tuna Bulgarcasındaki veçem [veçim] 'üçüncü' $(<* \ddot{u} c ̧+i m)$, toutom [töütöm] 'dördüncü' $(<*$ tö: $r t+i m)$ vb. biçimlerdeki $+(I) m$ sıra sayı ekiyle aynı olduğunu tespit etmiştir.

Aynı biçimler bazı Türkçe tekerlemerde de hem Başkurtçadaki gibi tekli olarak, yani birim, ikim vb. şeklinde, hem de Tatarcadaki gibi ikili olarak birem birem / ikem - ikem şeklinde görülürler (bkz. aşağıdaki (20)-(25) numaralı örnekler). Burada Tatarcadaki bürem-bürem / ikem-ikem (= Берәм-берәм / икәм-икәм) biçimleri ve Türkçedeki birem - birem / ikem - ikem biçimlerinin aynı olması, Türkçedeki biçimlerin Anadolu'nun çeşitli bölgelerine yerleşen Altın Ordu Kumanları tarafından getirilmiş olabileceğini düşündürüyor. Bu görüşü destekleyen tarihi verilere çalışmanın sonunda kısaca değineceğim.

34 Muhametşin / Hakimzyanov 1987: 67.

35 алтан-алтан 'altı-altı' biçimi aslen алтам-алтам biçimine geri gider $(n<m)$. Bu biçim Tatarca sayışmacadaki алтам biçimiyle aynıdır. 
Türkiye'de seyrek olarak görülen ve aşağıdaki tekerlemelerde geçen birem - birem / ikem - ikem, birem ikem biçimleri - bir ve iki sayılarıyla olan ilişkileri tahmin edilebilse de - bugün asıl anlamları artık tamamen unutulmuş uyaklı sözcüklerden başka bir şey değildir:

(20) birem birem - ikem ikem / kamçı boylu kara diken ... ${ }^{37}$

(21) birem birem -ikem ikem / hamsi bıyık kara diken / tomruk götlü doşgile / salla bunu çek şunu ${ }^{38}$

(22) Birem birem / İkem ikem / Demir diken / Ayna kuran / Zurna çalan /

Halp hulp / Altın top / Bundan başka / Oyun yok / Çıt mıt /

Nerden geldin / Ordan çık ${ }^{39}$

(23) Birem ikem / Kamçı dikem / Saram sakız / Doram dokuz / Tamam otuz ${ }^{40}$

(24) Birim birlik / ikim ikilik / üçüm gözlük / dördüm döne /

beșim beşik / ...11

(25) Birim birlik / ikim ikilik / üçüm üçlük /... ..... / dokuzum durak ${ }^{42}$

Yukarıda verilen örneklere ve açıllamalara dayanarak Türkiye Türkçesindeki, Tatarcadaki ve Başkurtçadaki gibi, Kazakçadaki birim ve Kuman-Kıpçakça sayışmacadaki bérem $~$ birem $(<*$ bir + im $)$ biçimlerini 1. tekil kişi iyelik ekli biçimler olarak değil, eskicil $+(I) m$ sıra sayı ekli biçimler olarak görmek gerektiği kanaatindeyim. Buna dayanarak Kuman-Kıpçakçadaki bérem $\sim$ bírem (< * bir+im), ékem íkem biçimlerinin asıl anlamlarının 'birinci', 'ikinci' olması gerektiğini, fakat $+(I) m$ sıra sayı ekinin zamanla unutulması nedeniyle bu ekle türetilmiş sıra sayı adlarının Kuman-Kıpçaklarda da muhtemelen 1. tekil kişi iyelik ekli biçimler olarak yorumlanmış olabileceğini düşünüyorum. Bu sebeple, Mándoky Kongur'un Kuman-Kıpçakçadaki bérem bírem, ékem íkem biçimlerini 1. tekil kişi iyelik ekli biçimler olarak yorumlamasını bir dereceye kadar anlamak mümkünse de buradaki $+m$ ekinin aslen 1. tekil kişi iyelik eki olmas1 gerektiği fikrine katılmıyorum. Bütün bu yukarıda söylenenlere dayanarak ve

37 Nevşehir'in Hacıbektaş ilçesinin Kösektaş köyünden derlenmiştir, Bk. http://www.kosektas.com/?Syf= 15\&cat_ id=110\&baslik_name=U2FsbGFuZ3XDpyAtIERyLiBTYWxpbSDDh2VsZWJp (erişim: Eylül 2012).

38 Giresun'dan derlenmiștir, bk. http://www.eksisozluk.com/show.asp?t=anlams\%C4\%B1z\%20tekerlemeler (erişim: Eylül 2012).

39 İzmir'den derlenmiştir, bk. http://www.delinetciler.net/forum/cocuk- oyunlari/136942-unutulmus-cocuk-oyunlari. html (erişim: Eylül 2012).

40 İstanbul'dan derlenmiștir, bk. http://www.zihnisinir.com/ZSU/tr/defsayfa.asp?sid=31 (erişim: Eylül 2012).

41 Yozgat'in Sorgun ilçesinden derlenmiştir, bk. http://www.sorgun.bel.tr/index.php?module=modul_tek\& modul=127\& cat=452 (erişim: Eylül 2012).

42 Rize'nin Ardeşen ilçesinden derlenmiştir, bk. http://www.webhatti.com/komik-seyler/553941-1-dir-1-oyunu-nasiloynanir.html (erişim: Eylül 2012). 
Türkiye'deki sayışmaca örnekleri yardımıyla Macaristan'ın Büyük Kumanistan bölgesinden derlenmiş olan Kuman-Kıpçakça sayışmacanın çevirisini ve son üç satırının rekonstrüksiyonunu şöyle yapabiliriz:

\begin{tabular}{|c|c|c|}
\hline (unmadaras) & ( & (çevirisi) \\
\hline 1. bérem bélö & 1. birim bilew & 1. Birinci(si), bileği \\
\hline 2. ékem égö & 2. ekim egew & 2. İkinci(si), eğe \\
\hline 3. öcsém üszök & \multicolumn{2}{|c|}{ 3. ̈̈çüm (üçim) üzük (üzik) 3. Üçüncü(sü), keçe örtü } \\
\hline 4. kertem tücsök & 4. törtüm (törtim) töşek & 4. Dördüncü(sü), döşek \\
\hline 5. becsém becsek & 5. beşim beşik & 5. Beşinci(si), beşik \\
\hline 6. állam hasad & 6. alttm aşık & 6. Altıncı(s1), aşık \\
\hline 7. csettem csetteg & 7. cetim ... (eksik) .. & 7. Yedinci(si), ... (eksik) ... \\
\hline 8. szegzem szenneg & 8. segizim senek & 8. Sekizinci(si), ağaç dirgen \\
\hline 9. togzom torcog & 9. toguzum torsuk (torsik) & 9. Dokuzuncu(su), kımız tulumu \\
\hline 10. hónom hagyta & $10 \ldots \ldots$ (eksik) $\ldots \ldots$ & $10 \ldots \ldots \ldots$ (eksik) ..... \\
\hline 11. gyürüm kapta & $11 \ldots \ldots$ (eksik) $\ldots \ldots$ & $11 \ldots \ldots \ldots$ (eksik) ..... \\
\hline 12. alcsik & 12. $a l c ̧ ı k$ & 12. Alçık \\
\hline 13. balcsik & 13. balçı & 13. Balçık \\
\hline 14. szencsig & 14. sen çık & 14. Sen çık! \\
\hline
\end{tabular}

Çalışmamızın sonunda, aslında Bulgar Türkçesine özgü olan birim, ikim gibi sıra sayılarının Kuman-Kıpçakçaya, Kazakçaya, Tatarcaya, Başkurtçaya ve Türkçeye nasıl geçtiğini anlamak için Kuman-Kıpçakların tarihine ve göçlerine çok kısa bir göz atmak gerekiyor.

Bilindiği gibi Volga Bulgarları, tarihi kaynaklarda 10. yüzyıldan itibaren anılmaya başlanıyor. 10. yüzyılın başından 1236'daki Moğol istilasına kadar Volga ve Kama nehirlerinin buluştuğu noktada gelişmiş bir devlet kurmuşlardı. Bu Volga Bulgar Devleti, Moğol istilasından önce o bölgenin tek ve en güçlü İslam devleti haline gelmişti. Moğolların 1236'da Avrupa'ya karş1 yaptıkları akınların ilk kurbanları ise Volga Bulgarları oldu. Bunun sonucunda Volga Bulgarları Mogollar tarafından kurulan Altın Ordu Devleti'ne tabi oldular. Fakat sadece Volga Bulgarları değil, Kuman-Kıpçaklar da Altın Ordu Devleti'ne tabi olmuşlardı. Altın Ordu Devleti, Kuman-Kıpçaklar, Volga Bulgarları, Peçenekler, Başkurtlar ve başka pek çok halklardan oluşuyordu. Volga Bulgarları, Altın Ordu Devleti içerisinde tamamen asimile olarak hem dilsel, hem de etnik bakımdan tamamen Kıpçaklaşırlar. Kıpçak dillerinde görülen pek çok Bulgar Türkçesi kökenli sözcük bu asimilasyon sürecinin bir sonucudur. Kuman-Kıpçakça, Kazakça, Tatar- 
ca, Başkurtça ve Türkçe sayışmaca ve tekerlemelerde karşımıza çıkan ve aslında Bulgar Türkçesine özgü olan birim, ikim gibi biçimler de büyük bir olasılıkla (muhtemelen bu biçimleri içeren tekerlemelerle ve/veya sayışmacalarla birlikte) işte Altın Ordu Devleti'ndeki bu asimilasyon süreçleri sonunda Kuman-Kıpçak halklarına geçmiş ve günümüze kadar ulaşmış olmalı.

Öte yandan Moğollar, Altın Ordu Devleti'ndeki çeşitli Türk boylarının yeniden teşkilatlanması ile meydana gelen Kuman-Kıpçak halklarının büyük bir bölümünü bugünkü Özbekistan'a, Kazakistan bölgesi'ne ve Orta Asya topraklarına yerleştirdiler. ${ }^{43}$ Buralara yerleştirilen Kuman-Kıpçaklar bu bölgelerdeki halkların, örneğin Kazakların, etnik yapısının oluşmasında önemli rol oynadılar. Bu nedenle (8) numaralı örnekteki Kazakça tekerlemede görülen birim, ikim gibi biçimlerin de bu bölgeye göç eden Altın Ordu Kuman-Kıpçakları tarafından getirildiğini söylemek sanırım yanlış olmayacaktır. Fakat Altın Ordu Kuman-Kıpçakları sadece doğuya değil Batı'ya, yani Doğu Avrupa'ya ve Balkanlar'a (Macaristan, Romanya, Bulgaristan, Makedonya) da göç ettiler. Macaristan Kuman-Kıpçaklarından kalan ve günümüze kadar ulaşan sayışmacayı da Volga Bulgarlarını asimile eden bu Altın Ordu Kuman-Kıpçakları getirmiş olmalılar.

Türkiye'de seyrek olarak görülen ve Tatarca, Başkurtça, Kazakça tekerlemelerdeki-lerle ayn olan birem - birem / ikem - ikem, birem ikem ve birim, ikim, üçüm gibi biçimler de muhtemelen Anadolu'ya dalgalar halinde ve sürekli olarak göç eden ${ }^{44}$ Altın Ordu Kuman-Kıpçakları tarafından getirilmiş olmalı.

$\mathrm{Bu}$ kısa tarihi açıklamalardan, söz konusu birim, ikim gibi biçimlerin Macaristan'a, Anadolu'ya, Kazakistan'a nasıl ulaştığını sanırım daha iyi anlamak mümkün olacaktır.

$\mathrm{Bu}$ çalı̧̧mada incelenen Kuman-Kıpçakça sayışmacanın ve yukarıda verilen diğer sayışmaca ve tekerlemelerin tabakalarını ve tiplerini aşağıdaki şemada görmek mümkün: 


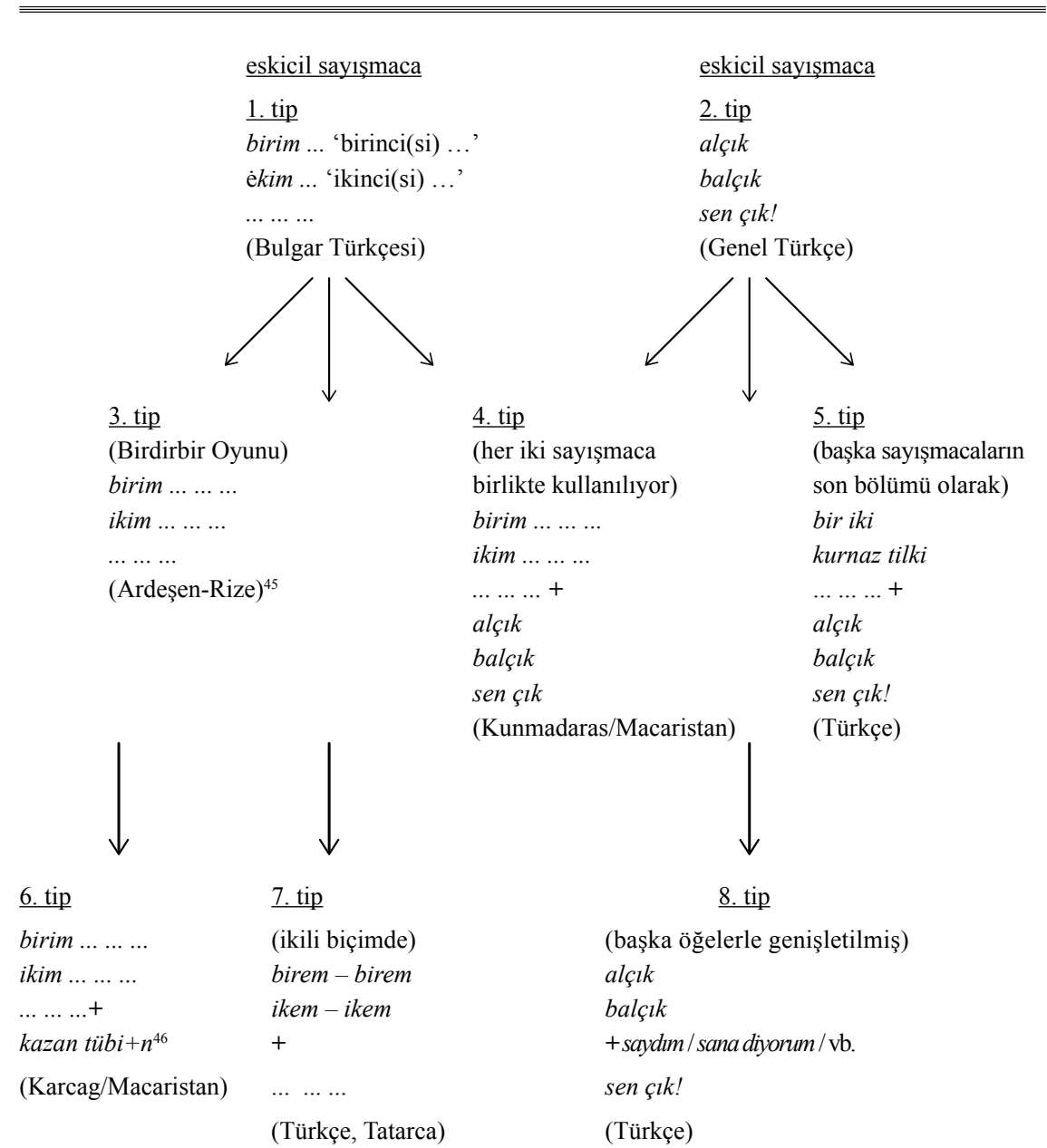

45 birim birlik / ikim ikilik / üçüm üçlük / dördüm dörtlük / beşim silmeden / altım elma / yedim yarma / sekizim sek sek / dokuzum durak / onum orak / onbirim yağh börek / onikisi soğan dolması / onüçüncüsü olsa da yesek / ondördüncüsü hamamda karılar / onbeşincisi birbirini kovalar (Ardeșen Kaymakamı Cemil Kılınç ve Ardeșen Belediye Başkanı Mümtaz Sinan’n derlemesi; bk. http://www.webhatti.com/komik-seyler/553941-1-dir-1-oyunu-nasil-oynanir.html (erişim: Eylül 2012). $46 \mathrm{Bu}$ (3) numaralı Macarca değişke, alçık / balçık / sen çık! ile biten (1) numaralı değişkeden farklı bir şekilde sonlanmaktadır. 


\section{Kaynakça}

Akın, T. B. (2010): Tekerlemelerden Seçmeler. Çocuklara Temel Eserler -1. İstanbul.

Aydemir, H. (2005a): The main pillars of the Turkic rhotacism-zetacism, I. sämiz, sämir-, sämri-, semre-. Studia Etymologica Cracoviensia, 2005/10: 15-34.

Aydemir, H. (2005b): Gagauzcada Kıpçakça Etkisi Üzerine. In: Turks and Non-Turks. Studies on the History of Linguistic and Cultural Contacts. (Haz.) Ewa Siemieniec-Gołaś / Marzanna Pomorska. Studia Tucologica Cracoviensia 10. Kraków 2005: 27-47.

Aydemir, H. (2009): Nyelvészeti megjegyzések a kun miatyánk Vincze-féle változatához. In: (Haz.) Szabolcs Rosta, A magyarországi kunok hagyatéka. Tanulmányok Horváth Ferenc 60. Születésnapja Tiszteletére. Kiskunfélegháza 2009: 259-272.

DS =Türkiye'de Halk Ağzından Derleme Sözlüğ̈̈ 1-12. Türk Dil Kurumu. Ankara.

Ercilasun A. B. (2007): Türkçede Benzerlik Bildiren +m Morfemi. Dil Araştırmaları Dergisi. Cilt 1, Say1 1, 2007: 9-20.

Erdal, M. (1993): Die Sprache der wolgabolgarischen Inschriften. Wiesbaden.

Farkas, O. (1987): Mongol csigacsont játékok. Keletkutatás. Ősz, 1987: 49-61.

Györffy, Gy. (1990): A kipcsaki kun társadalom a Codex Cumanicus alapján. In: A magyarság keleti elemei. Budapest 1990, 242-273.

Hisamitdinova, F. G. (2010): Mifologiçeskiy slovar' başkirskogo yazıka. Moskva.

Kakuk, Zs. (1993): Mándoky Kongur István. A kun nyelv magyarországi emlékei (Kumanische Sprachdenkmäler in Ungarn). Journal of Turcology 1 (1993/2) 1993: 305-325 (kitap tanitım1).

KklpBask. = Baskakov, N. A.: Karakalpakskiy yazık I. Materialı po dialektologii (tekstı i slovar'). Moskva, 1951.

Mándoky, K. İ. (1993): A kun nyelv magyarországi emlékei. Keleti örökségünk I. (Haz.) Bartha Júlia Ökrösné. Karcag.

Muhametşin, D. G. / Hakimzyanov, F. S. (1987): Ėpigrafiçeskie pamyatniki goroda Bulgara. Kazan'.

Mukusheva, R. (2008): Kun Miatyank (Kıpçakça Otçe Nas) ve Kıpçak Sayışmacaları (İştvan Mondaki Kongur'un İncelemeleri Temelinde). Türk Dünyası İncelemeleri Dergisi, Cilt: VIII, Say1 2: 141-149.

Stachowski, M. (1994): Urtürkisch *mč, * $n$ č und das jakutische Ordinalsuffix. Rocznik Orientalistyczny, XLIX Z. 2. 1994: 177-183.

Tekin, T. (1988): Volga Bulgar Kitabeleri ve Volga Bulgarcası. Ankara.

Torma, J. (1999): Bérem bélö, Íkem igő ...: Mándoky Kongur István emlékére. Karcag. 